\title{
Growth Trajectory and Adult Height in Children with Nonclassical Congenital Adrenal Hyperplasia
}

\author{
Malgorzata Gabriela Wasniewska ${ }^{a}$ Letteria Anna Morabito ${ }^{a}$ \\ Federico Baronio $^{b}$ Silvia Einaudic Mariacarolina Salerno ${ }^{d}$ Carla Bizzarri $^{c}$ \\ Gianni Russo $^{f}$ Mariangela Chiarito ${ }^{g}$ Anna Grandone ${ }^{h}$ Laura Guazzarotti $^{i}$ \\ Antonietta Spinuzza $^{a}$ Domenico Corica $^{a}$ Rita Ortolano ${ }^{b}$ Antonio Balsamo ${ }^{b}$ \\ Enrica Abrigo ${ }^{c}$ Barbara Baldini Ferroli $^{\mathrm{e}}$ Angela Alibrandi $^{j}$ Donatella Capalbo ${ }^{d}$ \\ Tommaso Aversa ${ }^{a}$ Maria Felicia Faienza ${ }^{9}$ Adrenal Diseases Working Group of \\ the Italian Society for Pediatric Endocrinology and Diabetology
}

\begin{abstract}
aDepartment of Human Pathology of Adulthood and Childhood Gaetano Barresi, Gaetano Martino University Hospital, University of Messina, Messina, Italy; bepartment of Women, Children and Urological Diseases, S. Orsola Malpighi University Hospital, University of Bologna, Bologna, Italy; ' Department of Pediatric Endocrinology and Diabetology, Regina Margherita Children Hospital, University of Turin, Turin, Italy; dPediatric Endocrine Unit, Department of Translational Medical Sciences, Pediatrica Section, Federico II University of Naples, Naples, Italy;

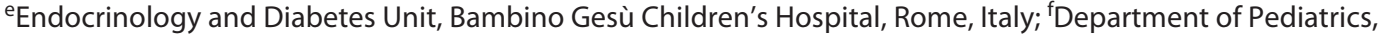
Endocrine Unit, Scientific Institute San Raffaele, Milan, Italy; ${ }^{9}$ Department of Biomedical Sciences and Human Oncology, Pediatric Section, University of Bari "A. Moro", Bari, Italy; hepartment of Woman, Child and General and Specialized Surgery, University of Campania Luigi Vanvitelli, Naples, Italy; 'Department of Pediatrics, University of Padua, Padua, Italy; 'Department of Economics, Unit of Statistical and Mathematical Sciences, University of Messina, Messina, Italy
\end{abstract}

\section{Keywords}

Nonclassical 21-hydroxylase deficiency · Growth and puberty · Adult height $\cdot 21$-hydroxylase deficiency $\cdot$ Severity of phenotype

\footnotetext{
Abstract

Background: Children with nonclassical congenital adrenal hyperplasia (NCCAH) often present increased growth velocity secondary to elevation of adrenal androgens that accelerates bone maturation and might compromise adult height (AH). Objective: The aim of the study was to analyze prognostic factors affecting growth trajectory (GT) and AH in chil-
}

dren with NCCAH. Methods: The study was a retrospective, multicentric study. The study population consisted of 192 children with a confirmed molecular diagnosis of NCCAH, followed by pediatric endocrinology centers from diagnosis up to $\mathrm{AH}$. Clinical records were collected and analyzed. $\mathrm{AH}$ (standard deviation score; SDS), pubertal growth (PG) (cm), GT from diagnosis to $\mathrm{AH}$ (SDS), and $\mathrm{AH}$ adjusted to target height (TH) (AH-TH SDS) were evaluated as outcome indicators using stepwise linear regression models. Results: The stepwise linear regression analysis showed that $\mathrm{AH}$ and $\mathrm{AH}$ TH were significantly related to chronological age (CA) $(p=$ 0.008 and 0.016$)$, bone age (BA)/CA ratio ( $p=0.004$ and $0.001)$, height $(\mathrm{H})(p<0.001$ for both parameters) at NCCAH karger@karger.com

(c) 2020 S. Karger AG, Base

www.karger.com/hrp

Karger ${ }^{\prime}=$
Malgorzata Gabriela Wasniewska

Department of Human Pathology of Adulthood and Childhood Gaetano Barresi Gaetano Martino University Hospital, Via Consolare Valeria

IT-98125 Messina (Italy)

mwasniewska@unime.it 
diagnosis, and TH ( $p=0.013$ and $<0.001)$. PG was higher in males than in females $(22.59 \pm 5.74$ vs. $20.72 \pm 17.4 \mathrm{~cm}, p=$ 0.002 ), as physiologically observed, and was positively related to height $(p=0.027)$, negatively to BMI $(p=0.001)$ and BA/ CA ratio $(p=0.001)$ at NCCAH diagnosis. Gender, genotype, biochemical data, and hydrocortisone treatment did not significantly impair height outcomes of these NCCAH children. Conclusions: The results of this study suggest that $\mathrm{AH}$ and GT of NCCAH patients are mainly affected by the severity of phenotype (CA, BA/CA ratio, and $\mathrm{H}$ ) at the time of diagnosis.

(c) 2020 S. Karger AG, Basel

\section{Introduction}

Nonclassical congenital adrenal hyperplasia (NCCAH) is an autosomal recessive disorder, secondary to a reduced function of enzymes involved in the adrenal steroid biosynthesis pathway. The most common enzymatic impairment involves pathogenetic variants of CYP21A2 gene that encodes for the 21-hydroxylase enzyme. In particular, the V281L, P30L, and P453S point mutations have been specifically characterized in this form, especially in the Italian population [1-3]. These mutations are associated with 30$50 \%$ of in vitro enzymatic residual activity, with usually normal cortisol and aldosterone production, but with mild postnatal androgen excess, leading to variable signs of hyperandrogenism that can manifest at any age $[4,5]$.

The prevalence of NCCAH is far more common than the classic form of 21-OH deficiency with an incidence of about 1:700 in the Caucasian [6] and Italian Population $[2,3]$. The main symptoms of the disease during childhood and adolescence include premature pubarche, cystic acne, hirsutism, and menstrual disorders $[2,5,6]$. In male patients, the disease may run as asymptomatic or poor-symptomatic, and the signs related to androgen excess might not always be clearly identifiable $[7,8]$. Contrary to the classic form of 21-OH deficiency, no acceleration of intrauterine growth was detected in NCCAH subjects [9].

Most children with NCCAH were reported to reach an adult height $(\mathrm{AH})$ within their target height $(\mathrm{TH})$, but accelerated growth and bone age (BA) advancement might, over time, lead to compromised $\mathrm{AH}$ [10-14]. A number of individuals with NCCAH could also remain asymptomatic and experience normal growth, puberty, and normal reproductive function, only coming to medical attention as a result of kindred studies [15].

A point of ongoing debate remains whether the glucocorticoid therapy could improve AH in NCCAH $[7,12]$.
The aim of our study was to analyze prognostic factors affecting growth trajectory (GT), pubertal growth (PG), and $\mathrm{AH}$ in a large population of Italian children with NCCAH.

\section{Patients and Methods}

This study was designed as a multicenter, retrospective review of medical records of 192 children (140 females, 52 males) with confirmed molecular diagnosis of $\mathrm{NCCAH}$, followed by 9 Italian Pediatric Endocrinology Centers from diagnosis until the reaching of $\mathrm{AH}$ during the period 1998-2017. Data have been recorded and entered in dedicated Microsoft Excel datasheet.

In these patients, clinical manifestation of androgen excess, such as precocious pubarche, growth, and bone maturation advancement (56.8\% of study population) were present at NCCAH diagnosis. Postnatal clitoromegaly ( $15 \%$ of females), hirsutism ( $12.8 \%$ of females), menstrual irregularity ( $15 \%$ of females), acne ( $14.5 \%$ of study population), and alopecia (1.04\% of study population) were found less frequently. In 4 males (7.69\%), gynecomastia was present. Nobody exhibited signs of virilization at birth. Only 14 patients (7.29\%) were diagnosed by family screening.

Standard ACTH stimulation test $(250 \mathrm{mg}$ of cosyntropin i.v.) with a measurement of both 17-hydroxy-progesterone (17-OHP) and cortisol at $60 \mathrm{~min}$ was used for the NCCAH diagnosis [16-18]. A 17-OHP peak $\geq 30 \mathrm{nmol} / \mathrm{L}$ was considered to be diagnostic for NCCAH. A stimulated cortisol level of less than $500 \mathrm{nmol} / \mathrm{L}$ (observed in 34 patients) might justify daily glucocorticoid supplementation and defined a condition at risk of adrenal failure in stress situations.

Genetic analysis was performed by the PCR sequencespecific oligonucleotide probe method as previously described [2]. The majority of patients $(89.1 \%$ of the study population) underwent hydrocortisone therapy with a median dose at start of $12.4 \mathrm{mg} / \mathrm{m}^{2} /$ day (range 10.2-25.2 $\mathrm{mg} / \mathrm{m}^{2} /$ day), after NCCAH diagnosis. A small number of patients (12 children: 7 females and 5 males) underwent high-dose hydrocortisone treatment (above 17-20 mg/ $\mathrm{m}^{2} /$ day), and this subgroup was also analyzed separately. The adequacy of the therapy was periodically monitored and based on clinical and laboratory data, in accordance with current guidelines [18].

The study population was divided by gender (males $27.1 \%$; females $72.9 \%$ ), treated and untreated with hydrocortisone (89.1\% treated; $10.9 \%$ untreated), and genotype 
Table 1. Demographic, clinical, and biochemical features at NCCAH diagnosis, at puberty, and at AH of study population (all and divided by gender)

\begin{tabular}{lcccc}
\hline Parameters median & $\begin{array}{l}\text { All cases, } \\
n=192\end{array}$ & $\begin{array}{l}\text { Males, } \\
n=52\end{array}$ & $\begin{array}{l}\text { Females, } \\
n=140\end{array}$ & $p$ value \\
\hline NCCAH diagnosis & & & & \\
$\quad$ Age at diagnosis, years & $7.45 \pm 3.72$ & $7.06 \pm 2.76$ & $7.59 \pm 4.01$ & 0.580 \\
Height (SDS) & $0.67 \pm 1.17$ & $0.99 \pm 1.17$ & $0.55 \pm 1.14$ & $0.019^{*}$ \\
BMI (SDS) & $0.43 \pm 1.03$ & $0.58 \pm 1.02$ & $0.36 \pm 1.02$ & 0.36 \\
BA/CA ratio & $1.49 \pm 2.36$ & $1.39 \pm 0.26$ & $1.53 \pm 2.77$ & $0.011^{*}$ \\
TH (SDS) & $-0.39 \pm 0.87$ & $-0.38 \pm 0.91$ & $-0.38 \pm 0.86$ & 0.943 \\
Basal 17-OHP during ACTH test, ng/mL & $21.1 \pm 21.76$ & $19.56 \pm 21.01$ & $21.64 \pm 22.07$ & 0.857 \\
Peak 17-OHP during ACTH test, ng/mL & $63.06 \pm 44.1$ & $59.74 \pm 40.69$ & $64.12 \pm 45.34$ & 0.616 \\
Puberty & & & & $0.19 \pm 1.95$ \\
Height (SDS) & $0.38 \pm 1.76$ & $0.78 \pm 1.17$ & 0.065 \\
PG, cm & $21.36 \pm 14.53$ & $22.59 \pm 5.75$ & $20.72 \pm 17.40$ & $0.002^{*}$ \\
Outcomes & & & & 0.980 \\
AH (SDS) & $-0.36 \pm 1.05$ & $-0.34 \pm 1.06$ & $-0.36 \pm 1.05$ & 0.050 \\
AH-TH (SDS) & $0.02 \pm 0.92$ & $-0.05 \pm 0.96$ & $0.05 \pm 0.89$ & 0.650 \\
GT (SDS) & $0.97 \pm 1.18$ & $1.26 \pm 1.29$ & $0.85 \pm 1.12$ & $0.011^{*}$ \\
\hline
\end{tabular}

NCCAH, nonclassical congenital adrenal hyperplasia; BA/CA ratio, bone age/chronological age ratio; $\mathrm{TH}$, targeted height; 17-OHP, 17-hydroxy-progesterone; PG, pubertal growth; $\mathrm{AH}$, adult height; $\mathrm{AH}$ - TH, adult height adjusted to targeted height; GT, growth trajectory; SDS, standard deviation score. The asterisk indicates statistically significant values $(p<0.05)$.

(29.68\% V281L homozygosis, 44.79\% compound heterozygosis with V281L, and $25.53 \%$ other mutations, such as P30L/P453S, P30L/P30L, P30L/P453S, P30L/L308iT, and $\mathrm{P} 30 \mathrm{~L} / \mathrm{D} 8 \mathrm{pb})$. Clinical, auxological, and biochemical data at the time of NCCAH diagnosis, at pubertal onset, at the end of puberty, and at the reaching of $\mathrm{AH}$ were collected by tertiary pediatric endocrinologists during each semiannual control visit in order to evaluate the GT.

Pubertal onset was defined by the appearance of pubertal signs: breast buds in girls and a testicular volume reaching $4 \mathrm{~mL}$ in boys. Precocious puberty was diagnosed when pubertal signs appeared before the age of 8 years in girls and 9 years in boys.

Height $(\mathrm{H})$ of the patients and of their parents was measured with the Harpenden-Holtain stadiometer. Auxological data were expressed in $\mathrm{cm}$ and standard deviation scores (SDSs) for age and gender, based on Italian growth standards [19]. BA was determined according to Greulich et al. [20] and puberty was assessed according to Marshall and Tanner [21, 22].

Patients' height was considered as adult when the increment was $<1 \mathrm{~cm}$ over 1 year or when BA was 15 years in girls and 17 years in boys. AH adjusted to genetic target height (AH-TH) SDS was calculated as the difference between AH SDS and the mean parental height (TH SDS).
TH was calculated using the formula: [father's height + mother's height] $/ 2 \pm 6.5 \mathrm{~cm}$ for male and female respectively.

GT estimated stature growth from diagnosis to the reaching of $\mathrm{AH}$ and was calculated as the AH SDS minus $\mathrm{H}$ SDS at diagnosis of NCCAH. PG $(\mathrm{cm})$ was calculated as $\mathrm{H}(\mathrm{cm})$ at the end of puberty minus $\mathrm{H}(\mathrm{cm})$ at the start of puberty.

For the hormonal analysis, blood samples were collected at 08:00 a.m. after an overnight fasting. Serum total cortisol, 17-OHP, and delta-4-androstenedione were measured by each individual participating center using radioimmunoassay with commercial kits.

\section{Statistical Analysis}

Numerical data were expressed as mean \pm SD, median and range, and the categorical variables as number and percentage. As the numerical variables were not normally distributed (as verified using the Kolmogorov Smirnov test), a nonparametric approach was used. We performed statistical comparisons first between male and female patients, then between hydrocortisone-treated and nontreated patients, and finally by genotype, applying the Mann-Whitney test for numerical parameters and the $\chi^{2}$ test with reference to categorical variables. 
Table 2. Simple correlation of different variables affecting delta AH-TH (SDS)

\begin{tabular}{ll}
\hline $95 \%$ confidence interval & \\
\hline variables & $p$ value \\
\hline Outcome delta AH-TH & \\
Age at diagnosis & 0.55 \\
H at diagnosis (SDS) & $0.014^{*}$ \\
BA/CA ratio & 0.12 \\
Birth length (SDS) & 0.780 \\
Birth weight (SDS) & 0.510 \\
BMI at diagnosis (SDS) & 0.270 \\
Bone age at diagnosis & 0.097 \\
H at pubertal onset (SDS) & $0.000^{*}$ \\
PG, cm & 0.07 \\
\hline
\end{tabular}

$\mathrm{AH}-\mathrm{TH}$, adult height adjusted to targeted height; $\mathrm{H}$, height; BA/CA ratio, bone age/chronological age ratio; SDS, standard deviation score.; PG, pubertal growth. The asterisk indicates statistically significant values $(p<0.05)$.

Finally, a stepwise multivariate linear regression model was estimated in order to identify the most significant predictors of 4 outcome of interest: AH (SDS), PG (cm), GT (SDS), and AH-TH. The predictor variables inserted in the models as covariates were age at diagnosis, gender, birth length (SDS), birth weight (SDS), height at NCCAH diagnosis (SDS), BMI at diagnosis (SDS), BA/CA ratio, genetic target (SDS), pubertal stage, basal 17-OHP level, 17-OHP peak after ACTH stimulation tests, delta-4-androstenedione levels, and hydrocortisone doses.

All statistical analyses were performed using SPSS 22.0 for Window package. A $p$ value smaller than 0.05 was considered to indicate statistical significance.

\section{Results}

\section{Overall Study Population/Characteristics}

The median age at NCCAH diagnosis in our study population was 7.1 years (range $3.0-19.0$ ) and $67.9 \%$ of patients were diagnosed during prepubertal age. Demographic, clinical, and biochemical features of the study population are shown in Table 1. At NCCAH diagnosis, the only differences among the 2 gender groups were higher $\mathrm{H}$ and $\mathrm{BA} / \mathrm{CA}$ ratio in male patients than females (Table 1). PG (cm) and GT (SDS) were significantly greater in NCCAH males than females, as expected and physiologically observed (Table 1). AH SDS and AH-TH SDS were not significantly different in both genders (Table 1).
AH-TH SDS was related with H SDS at NCCAH diagnosis $(p=0.014)$ and H SDS at start of the puberty $(p<0.001)$ (Table 2).

\section{Hydrocortisone Treatment}

Demographic, clinical, and biochemical features of the study population divided into treated with hydrocortisone and untreated are shown in Table 3. The majority of our NCCAH patients underwent hydrocortisone treatment $(89.1 \%) ; 87.9 \%$ of females and $92.3 \%$ of males underwent hydrocortisone therapy. In a small subgroup of 12 patients treated initially with higher dose of hydrocortisone, a significantly higher BA/CA ratio $(1.47 \pm 0.33$ SDS vs. $1.12 \pm 0.52$ SDS $p=0.01)$ and basal 17-OHP (35.1 \pm 28.9 SDS vs. $20.63 \pm 19.98$ SDS; $p=0.01)$ at NCCAH diagnosis were revealed, in comparison with others treated with standard dose. We observed that untreated patients (only 19 cases) were older and had a milder clinical and biochemical picture at the NCCAH diagnosis (Table 3).

A statistical comparison was performed; however, the disproportionate difference in group size might affect the reliability of the results obtained (Table 3). PG $(\mathrm{cm})$ and GT (SDS) results were similar between treated and untreated patients (Table 3 ), but untreated NCCAH patients presented a trend $(p=0.053)$ toward higher AH SDS than those who were on hydrocortisone replacement.

\section{Genotype/Phenotype Correlations}

Demographic, clinical, and biochemical features of the study population, divided into 3 subgroups according to different genotypes, are shown in Table 4 . The 3 subgroups were very similar among them, excepting for the baseline levels of 17-OHP, that were lower in the subgroup of homozygotes for V281L mutation (Table 4). Moreover, our results were in line with the findings from the literature that homozygotes for P30L mutation patients or compound heterozygotes with the second classical mutation generally had higher 17-OHP levels after the ACTH stimulation [23]; however, they were not statistically significant (Table 4). PG (cm), GT (SDS), and $\mathrm{AH}$ (SDS) were similar across the 3 genotypes (Table 4).

\section{Multivariate Regression Analysis of Growth \\ Parameters}

The results of the multivariate regression analysis are presented in Table 5. AH and AH-TH (SDS) resulted negatively related to age and $\mathrm{BA} / \mathrm{CA}$ ratio at NCCAH diagnosis and positively related to $\mathrm{H}$ SDS at NCCAH diagnosis (Table 5). PG $(\mathrm{cm})$ was related to the same parameters 
Table 3. Demographic, clinical, and biochemical features at NCCAH diagnosis at puberty and at AH of study population divided by treated and untreated

\begin{tabular}{|c|c|c|c|}
\hline Parameters median & $\begin{array}{l}\text { Treated, } \\
n=171\end{array}$ & $\begin{array}{l}\text { Untreated, } \\
n=21\end{array}$ & $p$ value \\
\hline \multicolumn{4}{|l|}{ NCCAH diagnosis } \\
\hline Age at diagnosis, years & $7.00 \pm 2.82$ & $11.10 \pm 6.95$ & $0.002^{*}$ \\
\hline Height (SDS) & $0.67 \pm 1.19$ & $0.68 \pm 0.921$ & 0.57 \\
\hline BMI (SDS) & $0.44 \pm 1.04$ & $0.32 \pm 0.93$ & 0.47 \\
\hline $\mathrm{BA} / \mathrm{CA}$ ratio & $1.52 \pm 2.47$ & $1.21 \pm 0.14$ & $0.04^{*}$ \\
\hline TH (SDS) & $-0.39 \pm 0.86$ & $-0.35 \pm 0.96$ & 0.62 \\
\hline Basal 17-OHP during ACTH test, ng/mL & $22.15 \pm 21.69$ & $12.69 \pm 21.05$ & $0.008^{*}$ \\
\hline Peak 17-OHP during ACTH test, ng/mL & $63.82 \pm 43.37$ & $56.81 \pm 51.29$ & 0.24 \\
\hline \multicolumn{4}{|l|}{ Puberty } \\
\hline Height (SDS) & $0.34 \pm 1.80$ & $0.72 \pm 1.39$ & 0.75 \\
\hline $\mathrm{PG}, \mathrm{cm}$ & $20.04 \pm 5.92$ & $38.16 \pm 49.03$ & 0.153 \\
\hline \multicolumn{4}{|l|}{ Outcomes } \\
\hline AH (SDS) & $-0.41 \pm 1.01$ & $-0.27 \pm 1.36$ & 0.053 \\
\hline AH-TH (SDS) & $-0.28 \pm 0.89$ & $0.57 \pm 1.07$ & 0.061 \\
\hline GT (SDS) & $1.00 \pm 1.20$ & $0.59 \pm 0.83$ & 0.951 \\
\hline
\end{tabular}

NCCAH, nonclassical congenital adrenal hyperplasia; BA/CA ratio, bone age/chronological age ratio; TH, targeted height; 17-OHP, 17-hydroxy-progesterone; PG, pubertal growth; AH, adult height; $\mathrm{AH}$ - TH, final height adjusted to targeted height; GT, growth trajectory; SDS, standard deviation score. The asterisk indicates statistically significant values $(p<0.05)$.

Table 4. Demographic, clinical, and biochemical features at NCCAH diagnosis at puberty and at AH of study population with comparison between the groups with different genotype

\begin{tabular}{|c|c|c|c|c|c|c|}
\hline Parameters median & $\begin{array}{l}\text { V281L } \\
\text { homozygosity, } \\
n=57\end{array}$ & $\begin{array}{l}\text { V281L } \\
\text { heterozygosity, } \\
n=86\end{array}$ & $\begin{array}{l}\text { Other } \\
\text { mutations, } \\
n=49\end{array}$ & $p$ value $^{\mathrm{a}}$ & $p$ value $^{\mathrm{b}}$ & $p$ value $^{c}$ \\
\hline Age at diagnosis, years & $7.95 \pm 2.76$ & $7.07 \pm 3.90$ & $7.89 \pm 4.23$ & 0.09 & 0.52 & 0.39 \\
\hline Height (SDS) & $0.69 \pm 1.08$ & $0.61 \pm 1.20$ & $0.81 \pm 1.20$ & 0.87 & 0.51 & 0.42 \\
\hline BMI (SDS) & $0.45 \pm 1.17$ & $0.42 \pm 0.97$ & $0.34 \pm 0.96$ & 0.88 & 0.73 & 0.84 \\
\hline $\mathrm{TH}(\mathrm{SDS})$ & $-0.41 \pm 1.01$ & $-0.32 \pm 0.82$ & $-0.44 \pm 0.82$ & 0.48 & 0.84 & 0.71 \\
\hline Basal 17-OHP during ACTH test, ng/mL & $12.71 \pm 11.52$ & $21.61 \pm 20.83$ & $29.96 \pm 28.38$ & $0.029^{*}$ & $0.002^{*}$ & 0.14 \\
\hline Peak 17-OHP during ACTH test, ng/mL & $57.42 \pm 50.07$ & $62.29 \pm 37.13$ & $71.75 \pm 49.25$ & 0.14 & 0.13 & 0.74 \\
\hline \multicolumn{7}{|l|}{ Puberty } \\
\hline Height (SDS) & $0.16 \pm 2.65$ & $0.42 \pm 1.13$ & $0.5961 \pm 1.32$ & 0.97 & 0.54 & 0.51 \\
\hline $\mathrm{PG}, \mathrm{cm}$ & $24.87 \pm 24.48$ & $19.90 \pm 5.23$ & $19.79 \pm 5.87$ & 0.21 & 0.37 & 0.98 \\
\hline
\end{tabular}

NCCAH, nonclassical congenital adrenal hyperplasia; BA/CA ratio, bone age/chronological age ratio; TH, targeted height; 17-OHP, 17-hydroxy-progesterone; PG, pubertal growth; $\mathrm{AH}$, adult height; $\mathrm{FH}$ - TH, final height adjusted to targeted height; GT, growth trajectory; SDS, standard deviation score. The asterisk indicates statistically significant values $(p<0.05)$. ${ }^{a}$ Homozygosity V281L versus heterozygosity V281L. ${ }^{b}$ Homozygosity V281L versus other mutations. ${ }^{c}$ Heterozygosity V281L versus other mutations. 
Table 5. Multivariate regression analysis of different variables affecting AH, PG, and GT in NCCAH children

\begin{tabular}{|c|c|c|c|c|}
\hline \multirow[t]{2}{*}{ Variables } & \multicolumn{4}{|c|}{ Multivariate analysis $95 \%$ confidence interval } \\
\hline & $\beta$-coefficient & lower limit & upper limit & $p$ value \\
\hline \multicolumn{5}{|l|}{ Outcome AH } \\
\hline Age at diagnosis & -0.13 & -0.22 & -0.04 & $0.008^{*}$ \\
\hline $\mathrm{H}$ at diagnosis (SDS) & 0.85 & 0.59 & 1.11 & $0.000^{*}$ \\
\hline $\mathrm{BA} / \mathrm{CA}$ ratio & -1.6 & -2.66 & -0.55 & $0.004^{*}$ \\
\hline \multicolumn{5}{|l|}{ Outcome PG } \\
\hline Gender & 3.73 & 0.78 & 6.68 & $0.014^{*}$ \\
\hline Birth weight (SDS) & 1.38 & -0.18 & 2.93 & $0.081^{*}$ \\
\hline $\mathrm{H}$ at diagnosis (SDS) & 2.54 & 0.3 & 4.78 & $0.027^{*}$ \\
\hline BMI diagnosis (SDS) & -2.76 & -4.33 & -1.19 & $0.001^{*}$ \\
\hline $\mathrm{BA} / \mathrm{CA}$ ratio & -13.28 & -20.52 & -6.04 & $0.001^{*}$ \\
\hline \multicolumn{5}{|l|}{ Outcome GT } \\
\hline Age at diagnosis & 0.230 & 0.150 & 0.300 & $0.000^{*}$ \\
\hline Birth length (SDS) & 0.180 & 0.010 & 0.340 & $0.038^{*}$ \\
\hline $\mathrm{H}$ at diagnosis (SDS) & 0.290 & 0.090 & 0.506 & $0.005^{*}$ \\
\hline $\mathrm{BA} / \mathrm{CA}$ ratio & 1.350 & 0.500 & 2.190 & $0.002^{*}$ \\
\hline 17-OHP peak & 0.007 & 0.002 & 0.012 & $0.008^{*}$ \\
\hline Hydrocortisone dose & 0.034 & -0.001 & 0.069 & 0.055 \\
\hline \multicolumn{5}{|l|}{ Outcome AH-TH } \\
\hline Age at diagnosis & -0.120 & -0.220 & -0.020 & $0.016^{*}$ \\
\hline $\mathrm{H}$ at diagnosis (SDS) & 0.820 & 0.550 & 1.110 & $0.000^{*}$ \\
\hline $\mathrm{BA} / \mathrm{CA}$ ratio & -1.820 & -2.910 & -0.740 & $0.001^{*}$ \\
\hline Hydrocortisone dose & -0.038 & -0.083 & 0.008 & 0.105 \\
\hline
\end{tabular}

NCCAH, nonclassical congenital adrenal hyperplasia; $\mathrm{H}$, height; BA/CA ratio, bone age/chronological age ratio; TH, targeted height; 17-OHP, 17-hydroxy-progesterone; PG, pubertal growth; $\mathrm{AH}$, adult height; $\mathrm{AH}-\mathrm{TH}$, adult height adjusted to targeted height; GT, growth trajectory; SDS, standard deviation score. The asterisk indicates statistically significant values $(p<0.05)$.

as $\mathrm{AH}$ (Table 5). Moreover, the multivariate regression analysis revealed that GT SDS was positively related to the birth length; age, $\mathrm{H}, \mathrm{BA} / \mathrm{CA}$ ratio, and $17-\mathrm{OHP}$ peak at ACTH test at NCCAH diagnosis (Table 5).

\section{Discussion/Conclusion}

Our study is one of the few that evaluated growth patterns and AH of NCCAH patients. We analyzed a large population of Italian NCCAH children, which allowed us to have a full evaluation of GT and to improve our knowledge about the auxological history of these patients. Increased growth velocity and advanced BA were the most significant symptoms of androgen excess in NCCAH children and they could influence GT and determine AH [24].

While it is well known that poor height prognosis in classical congenital hyperplasia patients could be significantly improved by the early start of appropriate gluco- corticoid and mineralocorticoid replacement therapy, the same could not be fully confirmed for NCCAH patients [25]. Most of the studies about this topic in NCCAH, in fact, often showed unclear and discordant results $[6-8$, $12,13]$.

Females were the strongly predominant gender group in our study population: this finding was not indicative of a significative prevalence of the disease in females, but it was probably due to the fact that the symptoms related to hyperandrogenism were often unrecognizable or difficult to identify in males, who are usually diagnosed later, especially during pubertal age, as previously described [11,22]. More evident and prominent clinical presentation of hyperandrogenism in females could explain such strong prevalence of girls in our study population. In our retrospective study, we also observed that the vast majority of male patients underwent hydrocortisone treatment and this therapeutic choice was probably influenced by the severity of androgen excess manifestations. 
As previously described, premature pubarche, associated with accelerated growth velocity and advanced BA, was the most common symptom at NCCAH onset in both sexes in our population [2, 3, 10, 24, 26]. Moreover, the presenting symptoms could vary by age at NCCAH diagnosis. During adolescence, acne and menstrual irregularities were the most common symptoms indicating the disease in females. Acne was also fairly frequent in adolescent males in our study population.

It emerged that the genotype could influence phenotype not only in classical form [27], but also in NCCAH, and that some kind of mutation could be responsible of a more severe or mild form of the disease $[1,8,9,23]$. The data indicated that, NCCAH children with mild/severe genotype exhibited more accelerated growth, BA, and earlier puberty than those with mild/mild genotype, but their AH resulted lower. Moreover, young females with $\mathrm{mild} /$ severe genotype also had more menstrual irregularities than females with the mild/mild genotype $[2,3,23$, $28-31$. In our study population, we did not find any evident correlation between genotype and phenotype, except for lower 17-OHP levels (basal and stimulated) in the subgroup of homozygotes for V281L mutation, probably due to major enzymatic residual activity $[1,32]$. The small number of compound heterozygote patients with severe mutations of CYP21A2 gene (only 21 cases) did not allow us to perform a valid statistical analysis. In our study, the comparison between patients treated with hydrocortisone and untreated ones did not evidence significant differences on GT, but the statistic value of these results is limited by the small relative size of the untreated group and perhaps by some initial bias in the choice to treat or not.

The role of hydrocortisone treatment on the achievement of AH was always debated. Previous literature suggested early diagnosis and initiation of glucocorticoids therapy to improve height outcome in NCCAH children $[7,24]$. Recent findings revealed that NCCAH patients did not always need long-term hydrocortisone treatment, especially those with a cryptic form $[10,18,31]$.

As the Endocrine Society Guidelines recommended, hydrocortisone treatment has to be usually considered in prepubertal children with an early and inappropriate pubertal onset with rapid progression of adrenarche and/or growth and/or BA. It could be also considered for adolescents who demonstrated important and clinically significant hyperandrogenism, in order to suppress adrenal production of androgens $[18,26]$.

Moreover, we find a small group of our study population treated with a dose above $17-20 \mathrm{mg} / \mathrm{mg} /$ day in hy- drocortisone equivalents, which exceeded the recommended dosage of the classical congenital hyperplasia guidelines from The Endocrine Society. This small group probably needed more high suppressive dose of glucocorticoids to obtain improvement in clinical signs of androgen excess [7].

It is important to underline that when daily glucocorticoids are initiated, especially at supra-physiological doses, hypotalamic-pituitary-axis will be suppressed, and the risk of adrenal crisis during severe stress will increase. For this reason, glucocorticoid stress dosing could be suggested also in NCCAH patients with a suboptimal cortisol response to cosyntropin $[10,26,31]$.

There are no studies in the literature about the bone status on glucocorticoid-treated patients with NCCAH, although many reports consider these subjects to be at risk for osteoporosis and fractures [33]. The replacement doses of glucocorticoids currently used in NCCAH patients seemed to have no great impact on bone [34].

Most of the patients of our study population underwent chronic hydrocortisone treatment, as previously recommended $[35,36]$. Our retrospective data analysis showed that treated NCCAH patients presented an earlier age at diagnosis of the disease, a worse biochemical picture than untreated ones, and a clinical presentation suggestive of severe androgens excess.

Untreated patients seemed to show a trend to reach a better $\mathrm{AH}$, so further and larger studies would be needed to confirm this condition. In this subgroup, the better height outcome was probably due to a milder phenotype. The severity of symptoms of androgen excess could influence the decision about the initiation of hydrocortisone therapy. Current consensus on NCCAH, which suggests not to treat in the absence of androgen excess and normal stimulated cortisol level and provided only stress dose cover, has changed our approach to this disease in recent years $[18,37]$. In our study population, we observed that treated NCCAH patients seemed to have not only poorer height outcome but, above all, might present full adrenal suppression associated with higher risk of adrenal crisis due to supra-physiological glucocorticoid substitution.

\section{Limitations of the Study}

The retrospective character of our protocol and the disproportion between the number of compound heterozygotes patients with severe mutations of CYP21A2 gene (only 21 cases) and other genotype and between treated and untreated patients are limitations of the study. 


\section{Conclusions}

The results of this study suggest that AH and GT of NCCAH patients are mainly affected by the severity of phenotype (CA, BA/CA ratio, and $\mathrm{H}$ ) at the time of diagnosis, whereas gender, genotype, biochemical data, and hydrocortisone treatment do not significantly impair height outcome of these NCCAH children.

\section{Statement of Ethics}

This retrospective study design was approved by the Ethics Committee of Gaetano Martino University Hospital, Messina. Approval No. 10-20.

\section{Conflict of Interest Statement}

The authors have no conflicts of interest to declare.

\section{Funding Sources}

This research did not receive any specific grant from any funding agency in the public, commercial, or not-for-profit sector.

\section{Author Contributions}

M.G.W and M.F.F.: prepared research project; L.A.M. and M.G.W.: wrote the paper; M.F.F.: performed critical review of the manuscript; A.A., M.G.W., D.C. and L.A.M.: performed statistical elaboration for the study; T.A. and D.C.: creation and construction of the database; F.B., S.E., M.S., C.B., G.R., M.C., A.G., L.G., A.S., R.O., A.B., E.A., B.B.F., and D.C.: patient selection and data collection. All the authors read and approved the manuscript.

\section{References}

1 Einaudi S, Napolitano E, Restivo F, Motta G, Baldi M, Tuli G, et al. Genotype, phenotype and hormonal levels correlation in non-classical congenital adrenal hyperplasia. J Endocrinol Invest. 2011;34(9):660-4.

2 Wasniewska M, Di Pasquale G, Rulli I, Salzano $G$, Caruso M, Indovina S, et al. In sicilian ethnic group non-classical congenital adrenal hyperplasia is frequently associated with a very mild genotype. J Endocrinol Invest. 2007;30(3):181-5.

3 Gialluisi A, Menabò S, Baldazzi L, Casula L, Meloni A, Farci MC, et al. A genetic epidemiology study of congenital adrenal hyperplasia in Italy. Clin Genet. 2018 Feb;93(2):223-7.

4 Balsamo A, Cacciari E, Baldazzi L, Tartaglia L, Cassio A, Mantovani V, et al. CYP21 analysis and phenotype/genotype relationship in the screened population of the Italian Emilia-Romagna region. Clin Endocrinol. 2000;53(1): $117-25$.

5 Azziz R, Owerbach D. Molecular abnormalities of the 21-hydroxylase gene in hyperandrogenic women with an exaggerated 17-hydroxyprogesterone response to short-term adrenal stimulation. Am J Obstet Gynecol. 1995;172(3):914-8.

6 New MI. Extensive clinical experience: nonclassical 21-hydroxylase deficiency. J Clin Endocrinol Metab. 2006;91(11):4205-14.

7 White PC, Speiser PW, et al. Congenital adrenal hyperplasia due to 21-hydroxylase deficiency. Endocr Rev. 2000;21(3):245-91.

8 Savaş-Erdeve Ş, Çetinkaya S, Abalı ZY, Poyrazoğlu Ş, Baş F, Berberoğlu M, et al. Clinical, biochemical and genetic features with nonclassical 21-hydroxylase deficiency and final height. J Pediatr Endocrinol Metab. 2017;30(7):759-66.
9 Balsamo A, Wasniewska M, Di Pasquale G, Salzano G, Baronio F, Bombaci S, et al. Birth length and weight in congenital adrenal hyperplasia according to the different phenotypes. Eur J Pediatr. 2006;165(6):380-3.

10 Nordenström A, Falhammar H. Diagnosis and management of the patient with nonclassic CAH due to 21-hydroxylase deficiency. Eur J End. 2019;180:127-45.

11 Wasniewska M, Raiola G, Galati MC, Salzano G, Rulli I, Zirilli G, et al. Non-classical 21-hydroxylase deficiency in boys with prepubertal or pubertal gynecomastia. Eur J Pediatr. 2008; 167(9):1083-4.

12 Eyal O, Tenenbaum-Rakover Y, Shalitin S, Israel S, Weintrob N. Adult height of subjects with nonclassical 21-hydroxylase deficiency. Acta Paediatr. 2013;102(4):419-23.

13 Pijnenburg-Kleizen KJ, Borm GF, Otten BJ, Schott DA, van den Akker EL, Stokvis-Brantsma WH, et al. Absence of clinically relevant growth acceleration in untreated children with non-classical congenital adrenal hyperplasia. Horm Res Paediatr. 2012;77(3):164-9.

14 Juan L, Huamei M, Zhe S, Yanhong L, Hongshan C, Qiuli C, et al. Near-final height in 82 Chinese patients with congenital adrenal hyperplasia due to classic 21-hydroxylase deficiency: a single-center study from China. J Pediatr Endocrinol Metab. 2016;29(7):841-8.

15 Kohn B, Levine LS, Pollack MS, Pang S, Lorenzen F, Levy D, et al. Late-onset steroid 21-hydroxylase deficiency: a variant of classical congenital adrenal hyperplasia. J Clin Endocrinol Metab. 1982;55(5):817-27.

16 Azziz R, Dewailly D. Diagnosis, screening, and treatment of nonclassic 21-hydroxylase deficiency. In: Azziz R, Nestler JE, Dewailly D, editors. Androgen excess disorders in wom- en. Philadelphia: Lippincott-Raven; 1997. p. 181-92.

17 Clayton PE, Miller WL, Oberfield SE, Ritzén EM, Sippell WG, Speiser PW. Consensus statement on 21-hydroxylase deficiency from the European society for paediatric endocrinology and the Lawson Wilkins Pediatric endocrine society. Horm Res. 2002;58(4):188-95.

18 Speiser PW, Arlt W, Auchus RJ, Baskin LS, Conway GS. Congenital Adrenal Hyperplasia Due to Steroid 21-Hydroxylase Deficiency: An Endocrine Society Clinical Practice Guideline. J Clin End Metab. 2018;103:404388.

19 Cacciari E, Milani S, Balsamo A, Spada E, Bona G, Cavallo L, et al. Italian cross-sectional growth charts for height, weight and BMI (2 to 20 yr). J Endocrinol Invest. 2006;29(7): 581-93.

20 Greulich WW, Pyle SI, Stanford CA. Radiographic Atlas of skeletal development of the hand and wrist. 2nd ed. Palo Alto, CA: Stanford University Press; 1959.

21 Marshall WA, Tanner JM. Variations in pattern of pubertal changes in girls. Arch Dis Child. 1969;44(235):291-303.

22 Marshall WA, Tanner JM. Variations in the pattern of pubertal changes in boys. Arch Dis Child. 1970;45(239):13-23.

23 Balsamo A, Baldazzi L, Menabò S, Cicognani A. Impact of molecular genetics on congenital adrenal hyperplasia management. Sex Dev. 2010 Sep;4(4-5):233-48.

24 Weintrob N, Dickerman Z, Sprecher E, Galatzer A, Pertzelan A. Non-classical 21-hydroxylase deficiency in infancy and childhood: the effect of time of initiation of therapy on puberty and final height. Eur J Endocrinol. 1997;136(2):188-95. 
25 Bizzarri C, Improda N, Maggioli C, Capalbo D, Roma S, Porzio O, et al. Hydrocortisone therapy and growth trajectory in children with classical congenital adrenal hyperplasia. Endocr Pract. 2017;23(5):546-56.

26 Falhammar H, Nordenström A. Nonclassic congenital adrenal hyperplasia due to 21-hydroxylase deficiency: clinical presentation, diagnosis, treatment, and outcome. Endocrine. 2015;50(1):32-50.

27 Balsamo A, Cicognani A, Baldazzi L, Barbaro M, Baronio F, Gennari M, et al. CYP21 Genotype, adult height, and pubertal development in 55 patients treated for 21-hydroxylase deficiency. J Clin Endocrinol Metab. 2003;88(12): $5680-8$.

28 Nandagopal R, Sinaii N, Avila NA, Van Ryzin C, Chen W, Finkielstain GP, et al. Phenotypic profiling of parents with cryptic nonclassic congenital adrenal hyperplasia: findings in 145 unrelated families. Eur J Endocrinol. 2011;164(6):977-84.
29 Ayalon-Dangur I, Segev-Becker A, Ayalon I, Eyal O, Israel S, Weintrob N. The many faces of non-classic congenital adrenal hyperplasia. Isr Med Assoc J. 2017 May; 19(5):317-22.

30 Weintrob N, Brautbar C, Pertzelan A, Josefsberg Z, Dickerman Z, Kauschansky A, et al. Genotype-phenotype associations in nonclassical steroid 21-hydroxylase deficiency. Eur J Endocrinol. 2000;143(3):397-403.

31 Wilson RC, Mercado AB, Cheng KC, New MI. Steroid 21-hydroxylase deficiency: genotype may not predict phenotype. J Clin Endocrinol Metab. 1995;80(8):2322-9.

32 Eugster EA, Dimeglio LA, Wright JC, Freidenberg GR, Seshadri R, Pescovitz OH. Height outcome in congenital adrenal hyperplasia caused by 21-hydroxylase deficiency: a meta-analysis. J Pediatr. 2001;138(1):26-32.

33 Ventura A, Brunetti G, Colucci S, Oranger A, Ladisa F, Cavallo L, et al. Glucocorticoid-induced osteoporosis in children with 21-hydroxylase deficiency. Biomed Res Int. 2013; 2013:250462.
34 Delvecchio M, Soldano L, Lonero A, Ventura A, Giordano P, Cavallo L, et al. Evaluation of impact of steroid replacement treatment on bone health in children with 21-hydroxylase deficiency. Endocrine. 2015 Apr;48(3):9951000.

35 Speiser PW, Dupont B, Rubinstein P, Piazza A, Kastelan A, New MI. High frequency of nonclassical steroid 21-hydroxylase deficiency. Am J Hum Genet. 1985;37(4):650-67.

36 Speiser PW, Dupont J, Zhu D, Serrat J, Buegeleisen M, Tusie-Luna MT, et al. Disease expression and molecular genotype in congenital adrenal hyperplasia due to 21-hydroxylase deficiency. J Clin Invest. 1992;90(2): 584-95.

37 Trapp CM, Oberfield SE. Recommendations for treatment of nonclassic congenital adrenal Hyperplasia (NCCAH): an Update. Steroids. 2012;77(4):342-6. 